\title{
City as Open Work
}

\author{
Claudia Chirianni
}

Department of Architecture (DiARCH), University Federico II, Italy

Copyright $@ 2017$ by authors, all rights reserved. Authors agree that this article remains permanently open access under the terms of the Creative Commons Attribution License 4.0 International License

\begin{abstract}
The scientific discoveries of recent decades and in particular those relating to Complexity Theory have led to recognize the city as a typical example of adaptive complex system. Urban and architectural design must face today this complexity and the substantial unpredictability of generative bottom-up processes that determine it. That is, design should be aimed not to produce a finished object but rather to trigger a processuality that welcomes and benefits from the creativity of the community that the project itself will host. A design, therefore, no longer prescriptive but aimed at orienting the spontaneous evolution of the city system. This means, above all, stop thinking about architecture as an immutable finished object and start to consider it as a continuous process, that is, to adopt a procedural thinking. This finds its best expression in programming languages that today seem the most effective tools to manage a design process leading to not a single outcome, but all possible outcomes.
\end{abstract}

Keywords Complexity, Open Work, Generative Process, Unpredictability

\section{Introduction}

The scientific discoveries of recent decades and in particular those relating to Complexity Theory have led to recognize the city as a typical example of adaptive complex system, whose global-scale transformations are determined from local interactions between the agents that compose it. A system, that is, where "agents residing on one scale start producing behaviour that lies one scale above them” [1, p.18]. Since in 1961, for the first time, Jane Jacobs defined the city in terms of organized complexity [2], it became clear that the evolutionary growth of the city is not driven by some principle of optimization imposed from the top, but rather "by the decisions and choices of the multiple agents that are involved in decision making. (...) Some are micro-agents, choosing where to live and work, while others operate at a higher level deciding on changes to transport infrastructure or the location of a large organization” [3, p. 68]. Urban and architectural design must face today this complexity and the substantial unpredictability of generative bottom-up processes that determine it. The planner can no longer pretend to govern such non-linear processes through traditional design tools, he has to reinvent not only his methodology but also the very idea of his role regarding the design process and the relationship with the community. Complex Adaptive Systems scholars not only encourage a bottom-up approach to design, but even claim that many of the choices related to the final layout of urban and architectural interventions should remain non-specified so that they can be developed locally by individuals, communities, organizations according to their actual goals and needs [4]. Actually designers are asked to lose control over their works, or rather to modify the way in which control is exercised. That is to say that the design should be aimed not to produce a finished object but rather to trigger a processuality that welcomes and benefits from the creativity of the community that the project itself will host. A project, therefore, no longer prescriptive but aimed at orienting the spontaneous evolution of the city system.

\section{Materials and Methods}

\subsection{Open Work and Open Plan}

Important reflections on how urban and architectural design can be reconciled with unpredictability and random were developed by Bruno Zevi during a debate on the theme "Art and Society" organized by the Institute of Philosophy in Rome in 1962. Zevi indeed notes how urban planning has proved to be inefficient just because of its inability to absorb the unforeseen transformations of the city and therefore suggests to adopt an open plan logic as an expression of a continuous planning method, which doesn't crystallize into a definitive drawing [5]. This idea of open plan was born evidently under the influence of the book Open Work written by Umberto Eco and published the same year. Eco, in this book, sees the integration between scientific and artistic methods as the ultimate reason for the redefinition of work-interpreter dialectic that characterizes the contemporary art research. According to Eco the open work poetics encourage "acts of conscious freedom on the part of 
the performer and place him at the focal point of a network of limitless interrelations, among which he chooses to set up his own form without being influenced by an external necessity which definitively prescribes the organization of the work in hand" [6, p. 35]. According to Eco every work of art is open, because it's subject to interpretation by the audience. The difference with the art of the past is that the contemporary artist is no longer limited to being passively subject to such condition of openness but elevates it to an expressly researched program. A program that becomes even more explicit in that sub-category of open works that are the works in motion, works, that is, susceptible to transformations and able to assume configurations not expected by the artist as determined by exogenous agents. This doesn't implies the abandonment to total randomness. A work in motion, in fact, "is the possibility of numerous different personal interventions, but it is not an amorphous invitation to indiscriminate participation. The invitation offers the performer the opportunity for an oriented insertion into something which always remains the world intended by the author" [6, p. 58]. A certain amount of control is, therefore, always present and perhaps necessary. The "loss of control" mentioned previously can occur at different times of the design process, implying the involvement of various types of interpreters. The choice of the interpreter and the time of his intervention to the process define the margin of error (as a deviation from the initial forecast) that the author is willing to accept. Therefore, control is still exercised but in a different way, that is, by creating the system of rules and general constraints within which the potential interpreter is free to act [7].

\subsection{Architectural Approaches to Complexity}

In recent years, architecture has investigated different ways and strategies to address the complexity of adaptive social systems and encourage the involvement of communities as interpreters. In general terms it is possible to identify two types of intervention of greater spread: one based on essentially ambiguous and indeterminate character of the architectural proposal, in order to encourage the free and creative interpretation by the community; the other, in line with the idea of work in motion described by Eco, even allows that the interpretation becomes proper manipulation and physical modification of the work. Among the most notable examples of the first type is certainly the Grindbakken project by architecture collective Rotor in the docks of Ghent, Belgium: "A master plan has been designed for the docks of Ghent. (...) Following this plan, a 160 meters long concrete structure, the Grindbakken - used in the past to transfer gravel and sand between ships and trucks - was about to be transformed into a multi-purpose area accessible to the public, supplied with water and electricity and painted white as an empty canvas for future activities" [8]. The work, therefore, is a blank canvas, a public space without specific destination of use or typological model that the community is free to use as they please. Emblematic example of the second type is Elemental's project Quinta Monroy where the same hosted community is called to finish the project, actually becoming the interpreter. The design solution proposed by Aravena, who responds in the first instance to the problem of the limited budget to be allocated to the work, finds in the unfinished a strategy of appropriation of territory and identity expression. "The challenge of our first project was to accommodate a hundred families using a subsidy of $\$ 7,500$ dollars that in the best of the cases allowed for thirty-six square meters of built space in a 5,000-square-meter site, which cost three times what social housing could normally afford. None of the solutions in the market solved the equation. So, we thought of a typology, as buildings, could make a very efficient use of land and as houses allowed for expansion" [9]. The limit of these proposals is that the issue of the complexity doesn't inform the design process nor is there a specific research of a language or spatial solutions that foster the evolutionary capacity of the work. An architecture that has this capability must be understood not as the outcome of a process, but as a process itself. The strategies of the indeterminate and the unfinished easily show their limitations when not accompanied by specific reflections on the compositional structure of the project. In Quinta Monroy such limit is expressed especially in the conception of common areas, defined by an extremely rigid settlement system, which unlike the housing units are not designed to be enriched by the creative intervention of the hosted community.

A possible third way is represented by some experiments carried out within the framework of computational design research. One paradigmatic example is represented by the Silk Pavilion, an experimental project designed and constructed at the MIT Media Lab by the Mediated Matter group (a group of researcher directed by Neri Oxman), where we see two levels of system interpretation, one by the computer (for the realization of the primary structure), the other by a biological system (silkworms that make the skin of the pavilion), in a perfect integration of computational and biological process. "Inspired by optimization processes in Nature (...) the Silk Pavilion is an architectural structure fabricated by digital fabrication technologies combined with the deployment of live silkworms. It explored the relationship between digital and biological fabrication on product and architectural scales." [10, p. 3]. " (...) Here, the relationship between the global, top-down design of a constricting "environment" designed artificially by the designer informs its local, bottom up material manifestation as portrayed by the biological organism (the silkworm)." [10, p. 10]. Therefore, also in this case the design process is not entirely bottom-up, this type of process occurs only at certain times of the entire design process, integrating with a more traditionally top-down approach. In fact, although often one tries to describe these new design methodologies as entirely bottom-up processes, modern design techniques typically combine top-down and bottom-up processes. This is not only 
inevitable but also desirable to ensure that the emergent behavior of the studied systems can be oriented towards positive results. If we compare this project to Quinta Monroy we can see some similarities, being understood the substantial difference between a real architectural project and an academic research. In both cases, in fact the designer realizes only a part of the work that will be subsequently completed by the interpreter (a human community in one case, silkworms in the other). The difference resides in the fact that, in the Silk Pavilion, the primary structure, resulting from a top-down design process, is already informed by the interpreter's creativity as a result of a systematic study of the behavior of silkworms. This primary structure is therefore not the result of a choice $a$ priori, but rather oriented to facilitate and maximize the creative skills of the interpreter on the basis of their previous analysis. In this case, therefore, the question of Complexity permeates the entire design process, using appropriate working methods and techniques.

\subsection{Procedural Thinking}

It's evident that traditional design methods are not capable of expressing the project as a process, since they involve a too large control margin and univocal outcome. Computer science can help the designer in this sense: programming languages have allowed and encouraged a new way of thinking, a procedural thinking that has its own specific language. The term procedural literature was first introduced by Michael Mateas to describe this potential as the ability to read and write processes and to give rise to a procedural aesthetic and representation of the world. "With appropriate programming, a computer can embody any conceivable process; code is the most versatile, general process language ever created. Hence, the craft skill of programming is a fundamental component of procedural literacy"[11, p. 80]. Thus, programming is not just a technical tool, is a way of representing/describing the world through algorithms: as procedural language it does not offer a single and unalterable vision of the events it is called to describe, but a range of possible options. Identifying the modality and the moments when the intervention of the computer can be useful or necessary, the interaction between man and machine can lead to the definition of open compositional systems otherwise unthinkable. In fact generative processes take shape starting from human-computer interaction. The program, as a series of instructions, implies a decision on the part of the computer: it is in this sense that it can be called an interpreter. The script, developed by the designer to describe the behaviours/processes of the system, is implemented by the computer that returns a potentially infinite set of possible, comparable and unexpected outcomes. It was this potential that induced many artists from the '50s and '60s to prefer computers to traditional mediums. Among these, Manfred Mohr, one of the pioneers of computer art, identifies four ways in which programming contributes to innovate the creative procedures and the approach to the aesthetic problems:

- Precision as part of aesthetical expression.

- High speed of execution and therefore multiplicity and comparativity of the works.

- The fact that hundreds of imposed orders and statistical considerations can be easily carried out by a computer instead of by the human mind, which is incapable of retaining them over a period of time, for example during plotting time (calculation time).

- The continuous feedback during a man-machine dialogue involves a learning process on the side of the human being, resulting in a clearer image of the creator's thinking and intentions” [12, pp.94-95].

The application of this computational logic to architecture offers new possibilities for the design process management, redefining the control modality on compositional systems and improving integration between different design scales and stages [7].

\subsection{Design Grammar for Spatial Design: Learning from the Past}

A generative approach to architectural design is already found in some experiments of modern architects, most notably Le Corbusier. His commitment in looking for a foundation for a design grammar in seriality and proportions, in fact, has greatly contributed to define a generative approach to design.

"Le Corbusier developed some grammatical principles, the 'Five Points of New Architecture' that could be applied across a range of design scenarios or to generative systems. Not yet stochastic, he was moving towards a systematised and ordered protocol for designing. These rules included use of columns, roof-gardens, and free plan design not reliant on strictures of the load-bearing wall made possible by the introduction of reinforced concrete, long windows, and free façades.

With The Modulor, Le Corbusier intended to define a harmonic measure on a human scale that was applicable to architecture and mechanics (...). The system, like any grammatical implication, relies on the applicant. (...) While systematic on one level, Le Corbusier's serial system resulted in disorientation and impracticality because it revolved around proportions of a $183 \mathrm{~cm}$ tall European male build -his system is inflexible and fundamentally flawed. On the other hand (...) he created a stochastic and potentially generative approach.” [13].

In this he certainly was influenced by Iannis Xenakis, who worked as an engineer at Le Corbusier's studio from 1948 to 1959. In the same years Xenakis also devoted himself to the study of musical composition, approaching the avant-garde movements of the time. Then developed a stochastic generative approach to the musical and architectural composition that has its foundation in logic and mathematics, such approach will be theorized in his work Formalized 
Music, Thought And Mathematics In Composition (1971) [14]. This artistic theory does not see in the application of probabilistic calculation a total abandonment to chance. The overall process is entirely predictable, even if the events that compose it are random.

Examples of generative approaches to architecture are also found in the architecture of the past as the Mosque of Cordoba. As Stan Allen notes, "in Cordoba (...) independent elements are combined additively to form an indeterminate whole. The relations of part to part are identical in the first and last version constructed. The local syntax is fixed, but there is no overarching geometric scaffolding. Parts are not fragments of wholes, but simply parts. Unlike the idea of closed unity enforced in Western classical architecture, the structure can be added to without substantial morphological transformation. Field configurations are inherently expandable: the possibility of incremental growth is anticipated in the mathematical relations of the parts" [15, p. 25]. It is the compositional structure of the Mosque of Cordoba, founded on interconnections of simple elements that have allowed the growth and manipulation in the course of more than eight centuries, without there being an alteration of the initial spatial conception. The mosque was genetically predisposed to growth and adaptation over time. Allen uses the example of Cordoba to introduce the concept of field condition he elaborated: "(...) we may suggest that a field condition would be any formal or spatial matrix capable of unifying diverse elements while respecting the identity of each. Field configurations are loosely bounded aggregates characterized by porosity and local interconnectivity. The internal regulations of the parts are decisive: overall shape and extend are highly fluid. Field conditions are bottom-up phenomena: defined not by overarching geometrical schemas but by intricate local connections. Forming matters, but not so much the forms of things as the forms between things" [15, p. 24].

The idea of field condition brings the theories related to complexity back to the proper field of action of architecture and urbanism. Based on the ideas of relational space and permutation, this concept helps to define possible compositional strategies capable of giving life to wide range of possibilities immanent in the systemic logics of the field itself. That is to say, it identifies a potential design methodology based on the definition of generative compositional pattern for the spatial design. Therefore, by operating at the fundamental level of the compositional structure of the space it would be possible to generate one or more sets of rules interconnected at the base of the architectural organism growth through modularity, proportions and logical-mathematical connections between the parts.

\section{Conclusions}

In view of the above it is deduced that, in order to promote architecture with adaptive and evolving capacities, we should redefine the design methodologies so that they give rise to open systems of relations rather than objects incapable of absorbing the transformations of the urban system in which they are inserted.

As we have seen, the science of complexity tells us that the city is essentially an expression of spontaneous bottom-up processes that traditional planning cannot actually govern. But while it is easy to recognize the failure of the latter especially in our suburbs, on the other hand it is fair to wonder if a "spontaneous", entirely bottom-up, growth would give rise to an uncontrollable and indefinite proliferation of slums. However, referring to Eco's definition of open work, we see that the free interpretation by the audience always and only takes place within the limits wanted by the author.

Therefore thinking about architecture and city as open works doesn't imply the total abandonment to randomness, but only orienting the spontaneous behaviours of the community rather than pretending to determine them, shifting the design paradigm from order to organized complexity. This means, above all, stop thinking about architecture as an immutable finished object and start to consider it as a continuous process, that is, adopt a procedural thinking. This finds its best expression in programming languages that today seem the most effective tools to manage a design process leading to not a single outcome, but all possible outcomes. Unfortunately, much of the architectural research in this area seems to have focused more on the problems of structural optimization and cladding systems rather than spatial composition and the issue of complexity remains confined into the design process, which is still, ultimately, finalized to a finished product to drop into the urban/social context. In most cases, there is no intention to create architecture with adaptive properties, able to co-evolve with the social environment, capable of future changes. But, when oriented to define a set of relations between building and city, between architecture and community, those design processes give birth to actual open works, architectures that can evolve and adapt to the urban and social system in which they are inserted. Generative design protocols in fact, operating at the fundamental level of the compositional structure of the project, may lead to identifying new compositional systems, more effective than traditional ones in acting as a trigger of processes and general system of constrains within which the freedom of interpretation of communities may occur.

\section{REFERENCES}

[1] Johnson, S. B. 2001. Emergence: The Connected Lives of Ants, Brains, Cities. Scribner. New York, NY.

[2] Jacobs, J. 1961, the Death and Life of Great American Cities, New York: Random House. 
[3] Allen, P. M. 2012, "Cities: the Visible Expression of Co-evolving Complexity”, in Portugali J. et al., Complexity Theories of Cities Have Come of Age. An Overview with Implications to Urban Planning and Design, Springer, 67-89.

[4] Bettencourt, L. 2013, the Kind of Problem a City Is, SFI Working Paper, Santa Fe Institute.

[5] Zevi, B. 1963. "Architettura e Società", De Homine, n.5-6, Sansoni, Firenze,118-128.

[6] Eco, U. 1962, Opera Aperta, Bompiani; English translation: Cancogni, A. 1989, The Open Work, Harvard University Press.

[7] Chirianni, C. 2016. "Design Out of Control”, in EURAU 2016 European Symposium on Research in Architecture and Urban Design: In Between Scales. EURAU 2016 Proceedings, Ion Mincu University of Architecture and Urban Planning, Bucharest, Romania, 377-385.

[8] Rotor, "Grindbakken". http://rotordb.org/project/2012_Grind bakken_expo

[9] Elemental, "Quinta Monroy, 93 Incremental Houses Complex".http://www.elementalchile.cl/en/projects/quinta-m onroy/
[10] Oxman, N., Laucks, J., Kayser, M., Gonzalez Uribe, C.D., and Duro-Royo, J. 2013. "Biological Computation for Digital Design \& Fabrication”, eCAADe: Computation and Performance, September 18-20, Delft University of Technology (TU Delft), Delft, the Netherlands, (31), 1-10.

[11] Mateas, M. 2008. "Procedural Literacy: Educating the New Media Practitioner”, in Davidson D., Beyond Fun, ETC Press, 80-96.

[12] Mohr, M. 1976. "Manfred Mohr”, in Leavitt, R., ed., Artist and Computer, New York Harmony Books, 94-95.

[13] Beilharz, K. 2004. "Designing Sounds and Spaces: Interdisciplinary Rules \& Proportions in Generative Stochastic Music and Architecture", the Journal of Design Research, Vol.4. Issue 2, 4 (3).

[14] Xenakis, I. 1971. "Formalized Music: Thought and Mathematics in Composition", translated by Christopher Butchers (chapters 1-6), G. W. Hopkins (chapter 7), and Mr. and Mrs. John Challifour (chapter 8). Bloomington and London: Indiana University Press.

[15] Allen, S. 1998, "From Object to Field.", Architecture After Geometry, Architectural Design, 24-31. 